\title{
O CORONEL E O PROFESSOR: O ENSINO PÚBLICO NA DINÂMICA DO SISTEMA CORONELISTA DE PODER NA REGIÃO DE COLONIZAÇÃO ITALIANA
}

\author{
Giovani Balbinot ${ }^{*}$ \\ lattes.cnpq.br/4352934267366624 \\ Jéssica Adriana Pacheco Groders** \\ lattes.cnpq.br/7218627726920854
}

\begin{abstract}
Resumo: Diferentes trocas de favores e práticas clientelistas são claramente observáveis durante o período republicano brasileiro. A fim de sempre manter um expressivo plantel de eleitores, os partidos republicanos lançavam mão das mais variadas técnicas para a manutenção da base sufragista. No Rio Grande do Sul uma das moedas de troca, e meio para preservação da base, estava relacionada ao ensino público e suas escolas. Tanto a localização, quanto os professores que ministrariam as "aulas públicas”, se tornaram moedas de barganha entre o Presidente do Estado, os coronéis locais e os eleitores. E tal ação é claramente percebida na região de colonização italiana, como apresenta o artigo a seguir.
\end{abstract}

Palavras-chave: Coronelismo; Educação; Rio Grande do Sul.

\section{THE CORONEL AND THE TEACHER: PUBLIC EDUCATION IN THE DYNAMICS OF THE CORONELIST SYSTEM POWER IN THE ITALIAN COLONIZATION REGION}

\begin{abstract}
Different exchanges of favors and clientelists practices are clearly observable during the Brazilian Republican period. In order to maintain an expressive constituency of voters, the republican parties used the most varied techniques to maintain the suffragist base. In Rio Grande do Sul one of the exchange coins, and a way for preserving the base, was related to public education and its schools. Both the location and the teachers who would teach the "public lessons" became bargaining chips between the President of the State, the local colonels, and the voters. And this action is clearly perceived in the region of Italian colonization, as presented in the following article.
\end{abstract}

\footnotetext{
* Doutorando em História pela Universidade de Passo Fundo, UPF (Brasil). Contato: giovanibalbinot88@gmail.com.

${ }^{* * *}$ Mestranda em História pela Universidade de Passo Fundo, UPF (Brasil). Contato: jessicagroders@gmail.com.
} 
Keywords: Coronelism; Education; Rio Grande do Sul.

\section{Introdução}

O período republicano no Rio Grande do Sul ganhou esferas e proporções particulares e isso se deve principalmente à influência que as ideias positivistas tiveram sobre tais paragens. Júlio de Castilhos, amparado na Constituição estadual de 1891, estabeleceu as bases de ação e controle do Partido Republicano Riograndense sobre o restante do governo e, principalmente, sobre as massas eleitorais. Fazendo isso largamente amparado no racionalismo científico de August Comte, porém com uma leitura própria sobre o que seriam as ideias do teórico francês.

Trabalhar com o período republicano do Rio Grande do Sul infere em se deparar com situações de comando, controle e demonstração de poder nas mais variadas esferas, e com a educação não poderia ser diferente. A formação intelectual daqueles que iriam compor as bases de ação do governo republicano era interesse direto do governo e dos coronéis que fomentavam as práticas de coerção e cooptação.

$\mathrm{O}$ artigo a seguir mostra como as ações de controle e incentivo à educação, se deram na região de colonização italiana do Rio Grande do Sul, a partir da análise de cartas emitidas pelo intendente municipal de Guaporé, Sr. Agilberto Attílio Maia, ao Presidente do estado, Sr. Antônio Augusto Borges de Medeiros, nas primeiras duas décadas do século XX. Isso já durante a segunda fase de governo de Borges de Medeiros, considerada por muitos historiadores como o período em que o mesmo se consolidou como chefe estadual e do Partido Republicano Riograndense, fato esse que se deu após a morte do grande e primeiro líder Júlio de Castilhos, ocorrida em 1903. 
Iniciamos nossa análise com a compreensão da importância, da busca e da criação escola pública na região de colonização italiana. Compreendemos que famílias, comunidades, cônsules, congregações religiosas e autoridades públicas, dentro de intensas relações de poder, concorreram para a concretização da escolarização. Entretanto, pretendemos apontar o foco de nossa apreciação para a dinâmica entre coronéis, intendentes, professores e colonos, que constituíram a escolarização como uma poderosa engrenagem na máquina de cooptação política.

\section{A importância da educação escolar na lógica positivista do PRR}

No exercício passado funccionaram quarenta e três aulas subvencionadas pelo Estado e Municipio, alem de seis Estadoaes, e no vigente funccionaram 56 subvencionadas pelo Estado e $\mathrm{Mu}-$ nicipio e mais seis estadoaes, verificando-se pois, no presente exercício, um acréscimo de 13 aulas, tornando-se ainda necessária a creação de novas escolas para o exercício vindouro, attendendo-se aos repetidos pedidos de chefes de familias, que, a exemplo dos demais, propõem-se a construcção de casas para sua installação e funcionamento, bem como para a moradia dos professores. (AHMG. Relatórios da Intendência do Município de Guaporé, 1915, p. 7).

Após as palavras do Cel. Agilberto Attílio Maia iniciamos nossa análise afirmando que, contrariamente ao que ampara a grande parte da historiografia sobre a República Velha no Estado, sim, o Rio Grande do Sul e, especificamente a região de colonização italiana, também apresentaram a dinâmica convencionada como sistema coronelista de poder. Percebemos nestes espaços a mesma tênue ou, muitas vezes, indistinta linha entre o espaço público e privado que marcou o coronelismo no restante do País. As fraudes, corrupções, clientelismos, prevaricações, trocas de favores ou atitudes de violência forneceram também a tônica da vida política coronelista nos municípios de origem colonial. 
A hierarquia do PRR e a estrutura de estado idealizada e materializada por Castilhos e Medeiros não demonstraram ser suficientemente fortes para impor uma ditadura palaciana efetiva. Desta forma, a elite dirigente necessitava estabelecer uma rede com os coronéis locais. As formas de cooptação e coerção dos eleitores e opositores, assim como o processo eleitoral, não poderiam ocorrer sem a atuação do poder privado local. Neste sentido, o poder central palaciano e os poderes locais coronelistas articularam e dispuseram nas suas práticas de cooptação e coerção de instrumentos mais efetivos de intervenção autoritária na esfera política e administrativa na sociedade, fato este garantido pela Constituição de 14 de julho e 1891. Estes instrumentos manifestaram-se no Poder Judiciário, na Brigada Militar, nos Conselhos Municipais, nas disposições dos orçamentos estadual e municipais manipulados e, dentre outras, uma das maiores engrenagens da máquina política coronelista estabelecida na região colonial italiana, a influência, condicionamento e manipulação da Educação.

Analisando o processo de estruturação do ensino na região de colonização italiana no Rio Grande do Sul, observamos que a juventude colonial fora, quase em sua totalidade, privada do acesso mínimo a escrita, a leitura e as quatro operações até a virada do século XIX para o XX. Embora a legislação acerca do processo de ocupação colonial de 1867 regulamentasse a criação de escolar de caráter público nos núcleos coloniais, mais do que iniciativas estatais, prevaleceram as iniciativas comunitárias, de associações de mútuo socorro, de congregações religiosas ou mesmo de agentes consulares. Entretanto, estas poucas iniciativas não supriam as necessidades por educação, abonando a grande maioria da juventude a ignorância do analfabetismo, das operações matemáticas ou, até mesmo, do idioma vernáculo.

Com a instituição do regime republicano, o Rio Grande do Sul passou a ser conduzido por uma elite vinculada ao ideário positivista, o que proporcionou uma nova compreensão das questões relativas à educação. No conjunto de políticas públicas, a educação delineou-se então como uma importante esfera de ação, sendo implementado um processo de di- 
latação progressiva do ensino primário, de acordo com os interesses que norteavam os dirigentes associados ao PRR e aos líderes positivistas. Desta forma, a educação passou a ser vista como um aspecto fundamental para preparar e viabilizar a reestruturação da sociedade gaúcha, dentro dos moldes de uma modernização conservadora, assim como a escola tornou-se o espaço ideal para a difusão da política positivista (LUCHESE, 2012, p. 667-679).

Borges de Medeiros, em 1904, afirmava que "[...] nenhum outro serviço tem igual dotação orçamentária, que excede à quinta parte da receita total [...]" (LUCHESE, 2012, p. 675). O jornal A Federação, em edição de 17 de fevereiro de 1913 ressaltava que

[...] o acto do governo, melhorando e diffundindo o ensino publico, é de molde a influir directamente sobre o progresso moral e material do Estado, ao mesmo tempo que será util tambem a sua educação política. (A Federação, 1913).

A dinâmica de controle da educação dentro das relações de poder coronelista determinava a localização das escolas públicas que beneficiariam uma determinada comunidade em detrimento de outra, uma vez que critérios qualitativos e pedagógicos, como da quantidade de crianças que frequentariam a escola a ser criada, pouco, na prática, fora um fator a ser considerado. A manutenção e ampliação do educandário obedecia a lógica eleitoral de prestígio e/ou oposição ao Intendente, assim como a presença nesta, ou naquela, comunidade/capela/linha de determinada liderança local, seja um proprietário de casa de comércio ou um proprietário agroindustrial, desde que inserido na bancada do PRR local, tornava-se critério a ser avaliado.

A indicação e nomeação de um professor passava obrigatoriamente pela sua inserção na rede de compromissos coronelista local, não se delineando como fatores essenciais a habilitação e a aprovação em concurso público. Entretanto, neste momento questionamos qual o local da escola e da escolarização na vida do imigrante colonizador? Ao propor a discussão sobre envergadura da escola pública como elo essencial na rede de compromissos coronelistas, fica claro que apenas conseguimos abranger 
o alcance desta dinâmica quando compreendemos o sentido e a importância da escola para os imigrantes que se estabeleceram na região colonial italiana.

\section{A relevância da educação formal para os colonos italianos: diferentes perspectivas}

Em uma abordagem primária do contexto colonial, observamos o binômio trabalho e fé como característica cultural central, sobrepujando os demais horizontes dos imigrantes e de seus descendentes. Os âmbitos predominantes da vida estavam diretamente ligados à colônia, ao trabalho, à terra e seus frutos, à produção, ao comércio e ao sustento da unidade produtiva, que simbolizavam a realização do sonho e do ideal do colono imigrado, ou seja, expressão de ser proprietário de terra, da colheita dos frutos a prosperidade material e social. Assim, aspectos como a escolarização na vida dos imigrantes e seus descendentes parecem ter sido delegados a um segundo plano, de menor importância em relação ao horizonte econômico.

Desta forma, a escola e o estudo não foram compreendidos como uma forma de ascensão social, muito menos como uma garantia da prosperidade econômica e da fortuna material, estas tidas como diretamente ligadas à propriedade da terra e ao trabalho agrícola e, em alguns casos, ao comercial ou agroindustrial. Desta forma, os ensinamentos fundamentais e considerados básicos para a vida ocorriam no seio da unidade familiar.

Partindo deste princípio, a historiografia especializada na imigração italiana para o Rio Grande do Sul delegou ao segundo plano os aspectos relativos à escolarização nesta região, realizando abordagens superficiais, delineando de forma constante a escola e a educação como fatores de segunda importância na vida do imigrante e seus descendentes.

O historiador Rovílio Costa, em obra de 1986, argumentava que as preocupações fundamentais dos imigrantes e seus descentes orbitavam 
as questões relativas à terra e a seus frutos, pois sobre eles incidiam a autêntica segurança, prosperidade e felicidade. A escola era vista como uma perda de mão-de-obra, pois a segurarem o lápis não estavam segurando a enxada. Os filhos na escola representavam a ausência de braços na lavoura. Além do investimento em material escolar, vestes e deslocamento representarem um valor considerável na economia familiar, devido ao relevante número da prole (COSTA, 1986).

E Olívio Manfroi, em relevante escrito de 1975, ressalta o desinteresse nas questões relativas à educação, tanto por parte dos imigrantes, quanto por parte das autoridades públicas, o que resultou em uma medíocre expansão do ensino nas regiões de colonização italiana (MANFRÓI, 1975). Observamos que, por um lado, o trabalho agrícola baseava-se no conhecimento empírico e operatório ensinado pelos próprios pais no trato com a terra, com as culturas e com os animais, por outro, os valores morais, éticos e sociais eram ensinados no âmbito familiar e na catequese religiosa. Assim, para a formação do jovem na região de colonização italiana, bastava a conjunção do binômio: fé e trabalho (LUCHESE, p. 667670).

Entretanto, apesar desta visão deveras consolidada, levantamos alguns pontos a serem considerados referentes à relevância da escola, e da educação formal, entre os imigrantes e seus descendentes na região de colonização italiana, que acreditamos suscitarem novas perspectivas sobre esta temática. Nossa apreciação aponta para uma contradição sobre a primeira hipótese: de que houve falta de interesse, tanto por parte dos colonos $^{1}$, quanto por parte das autoridades públicas ${ }^{2}$, nos pontos relativos à criação e desenvolvimento do ensino público.

1 "No intuito de auxiliar a acção fecunda do benemérito governo do Estado e consoan-
te ao programma que tracei, não tenho poupado esforços para disseminar o ensino
primário que frequentemente é reclamado pelas respectivas populações para não ve-
rem seus filhos criarem-se em completo analfabetismo". (AHMG. Relatórios da In-
tendência do Município de Guaporé. Intendente Agilberto Attílio Maia, ano de 1913,
p. 6).
2 "A educação é o mister deste governo. A nossa população é, actualmente, superior a
trinta e três mil almas, na sua maioria de origem extrangeira, esparsa em um territó-
rio de cerca de 2.200 km quadrados, de maneira que, se não continuarmos na diffu- 
Observamos constantes manifestações dos colonos, através da concessão do lote de terra, da doação dos materiais e do mutirão para a construção, para o estabelecimento das unidades escolares localizadas pelo interior das linhas. As requisições para o estabelecimento de "aulas públicas" delineavam-se tão constantes como as requisições para a nomeação de professores para estabelecer a docência nestas escolas. Assim como o considerável número destas mesmas escolas estabelecidas, mesmo com sua atuação e duração sendo, em muitos casos, temporária e restrita, fornecem subsídios para a compreensão da necessidade, do anseio e da extensão da escola na zona de colonização italiana (LUCHESE; KREUTZ, 2010, p. 227-258).

Conforme bem explica Terciane Luchese, é perceptível que a escola foi importante, pois houve iniciativas particulares florescendo por toda a região colonial, as cobranças às administrações públicas manifestaram-se constantemente e até é possível observar a formação de associações que atendessem a demanda escolar. Não se trata de uniformizar o processo escolar e as iniciativas envolvidas, mas sim de interrogar os indícios históricos (LUCHESE, 2012, p. 672).

Devido aos anseios e necessidades do elemento imigrante por educação, as práticas coronelistas de cooptação alcançaram contornos bastante extensos na região colonial. Indícios desta extensão podem ser encontrados nas consideráveis somas empregadas nessa área, constantemente expostas tanto nos discursos do Presidente do Estado, quanto dos coronéis a frente das intendências municipais.

Conforme exemplificado nas palavras do Cel. Agilberto Attílio Maia no Relatório da Intendência de Guaporé relativo a $1^{\circ}$ de outubro de 1915 a 30 de setembro de 1916, a educação apresentava-se como um dos principais gastos municipais, pesado, sobremodo, no orçamento municipal. Mencionando 64 aulas, relatava um investimento de 40:405\$000, destes 21:000\$000 por conta do Estado e 19:405\$000 advindos das receitas

são do ensino, lógico é que a maior parte da infância crear-se-á no analphabetismo, como tambem desconhecendo o idioma vernáculo”. (AHMG. Relatórios da Intendência do Município de Guaporé. Intendente Agilberto Attílio Maia, ano de 1915, p. 7). 
municipais. Entretanto, conforme as palavras do Coronel era necessidade e dever a realização de qualquer sacrifício para se não aumentar, pelo menos para manter o orçamento destinado à educação pública.

A despesa effectuada com os regentes das 64 aulas supraalludidas, a contar de $1^{\circ}$ de outubro de 1915 a 30 de setembro do corrente anno, foi de 40:405\$000; sendo - 21:000\$000 por conta do Estado 19:405\$000 pelos cofres municipaes.

Como vedes, srs. do Conselho Municipal, a verba destinada a ser despendida com o ensino publico do município pesa sobremodo em nosso orçamento; não obstante, longe de prescindil-a, de attenual-a mesmo, precisamos e devemos - quando não augmental-a, ao menos - conserval-a, ainda mesmo que para isto mister se façam, de nossa parte, ingentes sacrifícios (AHMG. Relatórios da Intendência do Município de Guaporé, 1916, p. 8).

Tamanho investimento justificava-se à medida que o controle sobre educação atribuía ao coronel três prerrogativas de importância capital para a elaboração de sua rede de compromissos e o fortalecimento de sua área de influência: não obstante o evidente progresso intelectual da população e a melhoria da condição de vida, os investimentos na área da educação agiam como eficiente ferramenta de cooptação de eleitores ao atender as constantes demandas dos imigrantes e seus descendentes pelo estabelecimento de aulas públicas, assim como também funcionavam, através do encerramento ou transferência da localização das aulas, como medida de punição para eleitores recalcitrantes ou insurgentes contra a autoridade coronelista local.

Os benefícios das nomeações de docentes para as referidas aulas públicas garantiam ao coronel atender as constantes demandas dos professores por exercer suas profissões, o que afiançava a inclusão de novos elos à rede de compromissos estabelecida pelo poder local. E, por fim, o estabelecimento de novas escolas permitia a alfabetização do elemento imigrante e de seus descentes, e assim a consequente formação e alistamento de novos eleitores.

Este contexto esclarece os motivos das constantes solicitações para a abertura de aulas públicas endereçadas ao Presidente do Estado. O Cel. Agilberto Attílio Maia, em carta de 1915 a Borges de Medeiros, esclarece 
que a abertura de aulas públicas apresenta vantagens reais e incalculáveis para o município de Guaporé, tanto para o avanço social do município, quando para a consolidação de sua rede de compromissos. Nas palavras do coronel, a ampliação do número de aulas públicas traria "vantagens reais e incalculáveis", uma vez que "o elemento proeminente é o italiano que em grande maioria conserva o idioma pátrio transmitindo-o aos filhos com postergação do idioma oficial”, e segue argumentando que "só - penso eu- pela difusão do ensino se poderá de modo mais fácil e mais seguro tornar brasileiros os netos da gloriosa pátria” (IHGRGS, 1915, Documentos 02460 e 02468).

O Cel. Thomas José Pereira Júnior, em missiva de 1906 dirigida ao Presidente do Estado, lembra a Borges de Medeiros a "promessa que me fez, a qual consiste em promover para este município, duas aulas do sexo masculino afim de serem localisadas nos logares denominados Sapé e Tangerinas". Seguindo a mensagem, o Cel. Thomas Pereira justifica sua contumácia alegando que a abertura destas duas aulas públicas viria de modo a "saldar sérios compromissos políticos por mim contrahidos há muito tempo" (IHGRGS, 1903, Documento 10393).

Novamente o Cel. Thomas José Pereira Júnior, reitera e insiste na necessidade do cuidado da educação no município. Em carta enviada de Venâncio Aires a Borges de Medeiros de 1903, persiste em relação ao "pedido que verbalmente tive a honra de fazer-vos ultimamente quando ahi estive, e depois por telegrama", ressaltando "sobre a conveniência da creação de mais três aulas neste município" pois o estabelecimento destas aulas demostrava ser "necessidades que se impõem ao vosso patriotico e honrado governo que, estou certo, não descuidara de prove-las, como medida de utilidade publica”, finalizando sua carta destacando que "as aulas cuja creação tomo a liberdade de mais uma vez pedir, devem ser localisadas no lugar denominado Sapé e nas linhas Theresinha e Isabel, o $1^{\circ}$ para o sexo masculino e as demais mixtas" (IHGRGS, 1903, Documento 10393$)$.

Desta forma, compreendemos que as solicitações dirigidas a Borges de Medeiros eram constantes devido serem também constantes os apelos 
dirigidos aos coronéis em favor da abertura de aulas públicas. Logo, uma das principais engrenagens da máquina de cooptação política instituída pelos coronéis da região de colonização italiana delineava-se como o domínio sobre a educação, sendo a prerrogativa concedida pelo presidente do Estado sobre a instituição das aulas uma indubitável e extraordinária forma de cooptação dos imigrantes e seus descendentes, cristalizando e expandindo o prestígio e a influência dos coronéis coloniais.

Na região de colonização italiana, observamos que as aulas públicas foram estabelecidas em salas/casas de particulares alugadas ou, de forma preponderante, edificadas pelos próprios esforços comunitários. Nas sedes municiais, algumas aulas funcionaram junto ao prédio das prefeituras municipais, que abrigavam também a estrutura administrativa da intendência, o tribunal e aos fundos, ou abaixo, a prisão municipal, antes do estabelecerem prédio próprio.

Entretanto, notoriamente as aulas públicas estavam situadas nas zonas rurais, adjunta a uma capela ou propriamente na capela, principal espaço de sociabilidades das linhas coloniais. Eu seu aspecto físico, tratavam-se de construções simples, cujos espaços, materiais e mão de obra que fossem necessárias para suas edificações partiam das associações das próprias famílias interessadas no estabelecimento das aulas em suas comunidades. Os próximos passos delineavam-se em vê-las alcançar os benefícios de serem providas pelo poder público. Neste ponto a figura do coronel, na maior parte dos casos também intendente municipal, ao prover o funcionamento destas aulas públicas perpetrava uma de suas principais formas de cooptação dos imigrantes e seus descendentes (LUCHESE, 2012, p. 664-670).

Observar a educação na região de colonização italiana através deste prisma nos permite a compreensão das constantes preocupações dos coronéis locais com o ensino público. A zona colonial jamais se figurou como tranquilo celeiro de votos para o borgismo. Se, por um lado, a região integrou o sistema coronelista de poder porque o Estado o integrava como um todo, por outro, sempre desempenhou um fator de instabilidade para o comando central da rede de compromissos borgista, por vezes 
mais complexa de dirigir do que as cisões habituais e constantes verificadas no interior das elites dirigentes, comuns na região da campanha (AXT, 2011, p. 132).

Assim, os coronéis da região colonial utilizavam suas prerrogativas sobre a abertura de aulas públicas como forma de cooptação das populações coloniais, ou como forma de repreensão para eleitores recalcitrantes, ou insurgentes, contra a autoridade coronelista local por meio da extinção, ou transferência, da localização das aulas de uma linha ou comunidade para a outra. Da mesma forma, a abertura de aulas públicas poderia prestigiar ou denegrir a imagem, influência e o prestígio do coronel. Caso as constantes solicitações endereçadas aos coronéis fossem ignoradas, poderiam tornar-se fatores de instabilidade gerando descontentamentos, muitas vezes manifestado nas urnas.

Nos relatórios anuais elaborados pela Intendência do Município de Guaporé, a educação é constantemente ressaltada, assumindo status de primeira ordem tanto nas palavras do Cel. Agilberto Attílio Maia3, quanto do presidente do Estado Antônio Augusto Borges de Medeiros. 4 Nos Relatórios da Intendência do Município de Guaporé, ano de 1917, o Cel. Agilberto Maia destaca que, especialmente nos lugares como a região de colonização italiana onde "o elemento predominante é o extrangeiro", a

3 "No intuito de auxiliar o benemérito governo do Estado, que tantos esforços faz no sentido de combater a praga do analphabetismo, julguei meu dever instalar, no vasto território do município, o maior numero possivel de aulas para a instrucção elementar. Recebi muitos pedidos de escolas, assignados por numerosos habitantes, porém, foi-me impossível attender a todos. A administração municipal durante o corrente exercício tem auxiliado 13 escolas constantes do quadro". AHMG. Relatórios da Intendência do Município de Guaporé. Intendente Lucano Conedera, ano de 1910, p. 34 .

4 "Por esse modo, a direcção governamental do egregio dr. Borges de Medeiros apresenta-se inspirada dos mais elevados sentimentos republicanos, procurando proprocionar ao povo riograndense as condições indispensaveis do ensino publico, mediante o qual possam os filhos desta terra comprehender cada vez mais os seus direitos e deveres civicos. Não podiamos ficar para traz, no caminho da evolução, tratando-se de assumpto de tanta importancia como este, e o governo progressista do nosso digno Chefe não poderia ser indifferente a esse movimento do mundo civilisado". A Federação, Porto Alegre, 17 de fevereiro de 1913. Ano 1913 - Arquivo ooo41. Disponível em <http://memoria.bn.br/hdb/periodico.aspx>. Acesso em $1^{0}$ abr. 2015 . 
difusão do ensino está “como uma das múltiplas preoccupações que mais e mais deve atuar no espirito do administrador", "illuminando a intelligencia dos nossos patrícios com as luzes do saber que poderemos accender-lhes n'alma a chamma do patriotismo" (AHMG. Relatórios da Intendência do Município de Guaporé, 1917).

De acordo com os positivistas que sustentavam ideologicamente a ação dos governos do PRR, o coronel persiste acentuando que "Immerso nas trevas da ignorância ninguém, jamais, saberá comprehender [...] os seus próprios deveres cívicos e responsabilidades sociais”, deste modo "espalhar o ensino por todos os ângulos do Rio Grande do Sul tem sido e continua sendo uma das mais fortes cogitações do honrado e benemérito governo do Estado", assim como "é o preclaro Dr. Borges de Medeiros" (AHMG. Relatórios da Intendência do Município de Guaporé, 1917, p. 4).

Estas alocuções devotadas sobre a educação, constantemente presente nos relatórios das intendências, nas páginas do periódico A Federação e mesmo nos discursos dos coronéis e presidente do estado, abrigam, em suas entrelinhas, motores mais políticos que o progresso econômico e social, ascensão do espírito ético e o desenvolvimento do patriotismo nos elementos estrangeiros. Firmino Luiz Gomes de Abreu, proprietário de um notário na cidade de Antônio Prado, destina reveladora missiva ao presidente do Estado em 23 de maio de 1905 onde, após alegar a precariedade das rendas de seu cartório, solicita a Borges de Medeiros a indicação de um filho seu para ministrar aulas em alguma escola do interior de Antônio Prado, ou de Caxias do Sul.

Desejando approveitar o ensejo que ora se appresenta de melhorar as precárias circunstancias de minha família, devido a iniqüidade de rendas em meu Cartorio, venho a presença de $\mathrm{V}$. Excia. pedir vossa valiosíssima proteção para um filho meu, Affonso de Abreu, no proximo concurso para provimento de aulas publicas ruraes neste município ou na de Caxias. Convencido que não deixará V. Excia. de proteger a um funccionario que presa de ser fiel cumpridor de seus deveres, subscrevo-me. De. V. Excia.Am ${ }^{\circ} \mathrm{V}^{\mathrm{o}}$ e $\mathrm{C}^{\mathrm{o}}$, Firmino Luiz Gomes de Abreu (IHGRGS, 1905, Documento 00146). 
Como segundo ponto de análise, ressaltamos que as nomeações de professores para o exercício do magistério nas aulas públicas municipais e estaduais delineavam-se como métodos prezados e eficazes nas construções das redes de compromissos que sustentavam a ação dos coronéis da região de colonização italiana. A nomeação, para cargos do magistério da alçada estadual e municipal, de pessoas indicadas pelo coronel não era só demonstração de influência e autoridade. Permitia-lhe também reforçar e expandir os laços clientelísticos de submissão e fidelidade dos imigrantes e seus descendentes. Além disto, colocava sob seu controle direto órgãos que representavam o poder público estadual nos municípios, no caso, as escolas.

As requisições para nomeações em exercer o magistério delineavam-se tão constantes, quanto às solicitações para o estabelecimento das aulas públicas. Ressaltamos que estas duas práticas estavam diretamente associadas. Por um lado, a nomeações para o magistério promoviam o estabelecimento de importantes fontes de rendas para correligionários que se agregavam à rede de compromissos locais. Por outro, atendiam anseios e demandas dos eleitores por educação, em especial, do elemento imigrante disperso pelos distritos e linhas da área rural do município (AXT, 2011, p. 135).

A missiva enviada pelo Cel. Thomas Pereira a Borges de Medeiros é deveras ilustrativa deste contexto. Além de solicitar a nomeação da Professora Amélia Meneses de Bittencourt para reger aula pública estabelecida no interior de Venâncio Aires, argumenta que a "moça está habilitada para exercício effectivo de magistério e no tempo determinado se apresentara a concurso para esse fim". Nada obstante, continua em sua missiva delineando a urgência desta nomeação, pois o preenchimento desta vaga irá "attender a compromissos há muito contrahidos com os habitantes da zona onde estaella situada”.

Exmo. Snr. Dr. Antonio Augusto Borges de Medeiros

Venho hoje a vossa respeitável presença afim de impetrar-vos a nomeação de Da. Amelia Meneses de Bittencourt para reger a décima aula mixta situada nos subúrbios desta Villa.Essa moça 
está habilitada para exercício effectivo de magistério e no tempo determinado se apresentara a concurso para esse fim.

Mas tornando-se urgente o preenchimento dessa aula vaga para attender a compromissos há muito contrahidos com os habitantes da zona onde estaella situada. Peço-vos por isso essa nomeação e espero ser attendido com a possivel brevidade.

Saudações cordiais do vosso co-religionario e amigo att.

Thomas José Pereira Junior (IHGRGS, 1903, Documento 10390).

A profundidade desse vínculo de lealdade e prestígio ao coronel e ao partido estabelecido pela nomeação do quadro de professor pode ser compreendida através das palavras de Geraldina de Moraes, moradora de Antônio Prado, que remete carta a Borges de Medeiros em 1907 agradecendo a nomeação de sua filha, Carlinda de Moraes Pinto, para a função de professora de Carazinho, município de Passo Fundo. Segundo a autora, o pedido, bondosamente atendido, afasta a numerosa família da educadora da miséria, estabelecendo fortes vínculos desta com o coronel local, Innocencio de Mattos Miller, responsável pela intermediação da nomeação, e o presidente do Estado, Sr. Borges de Medeiros.

Tendo V. Excia. bondosamente attendido a meu pedido, nomeando minha filha Carlinda de Moraes Pinto, como professora de Carazinho, no município de Passo Fundo, cuja nomeação vem livrar numerosa família da miséria a que esta sujeita. [...]

Antonio Prado, 19 de Maio de 1907

Geraldina de Moraes (IHGRGS, 1907, Documento 00152).

A distribuição de benefícios ligados à educação, na região de colonização italiana, assim como na dinâmica coronelista como um todo durante a República Velha, obedecia a critérios diretamente ligados ao grau de inserção dos candidatos na rede de compromissos do coronel local, assim como os serviços prestados à facção e ao partido, sobretudo às eleições.

Conforme nossa compreensão, a base da dinâmica do coronelismo, como modelo de relações de poder e autoridade, envolvia uma complexa rede de relações que permeava todos os níveis de atuação política durante a República Velha. Observamos um sistema de reciprocidade envol- 
vendo trocas de compromissos, entre os intendentes municipais/coronéis, fornecedores dos favores e influências políticas, e o eleitorado cooptado, que nesta dinâmica hipotecava seu apoio político. A nomeação de juízes de distrito, comarca e superior tribunal, assim como promotores, delegados, policiais de todas as ordens, professores, coletores de impostos, notariados e registros gerais, etc., dependia diretamente da inserção do pretendente na rede de compromissos coronelista, sendo o requisito aprovação em concurso, uma formalidade simbólica e burocrática.

O Cel. Thomas Pereira, em carta de Venâncio Aires enviada em 1906, solicita a Borges de Medeiros a inclusão dos Professores Frederico Guilherme Jaeger e Antônio Mariante de Campos, pois estes foram "ultimamente aprovados em concurso, e por mim indicados para aula das linhas Sapé e Tangerinas".

\section{Ilustre cidadão Dr. Antonio Augusto Borges de Medeiros}

Peço-vos para não esquecer de incluir no respectivo quadro, os professores Frederico Guilherme Jaeger e Antonio Mariante de Campos, ultimamente aprovados em concurso, e por mim indicados para aula das linhas Sapé e Tangerinas.

Saudações cordeaes do vosso co-religionario e amigo

Thomas Pereira (IHGRGS, 1906, Documento 10398)

O quadro de professores dividia-se em duas categorias: concursados e substitutos. Apesar de os concursados possuírem maiores garantias, nem por isso tornavam-se menos dependentes da rede de compromissos, uma vez que tanto as concretizações de suas nomeações, quanto as suas situações posteriores, dependiam diretamente de suas relações com o poder local. Repetidamente os aprovados no concurso eram conhecidos e indicados antes mesmo da exposição do edital de concurso para o provimento da vaga. Além disso, mesmo após a aprovação, havia uma ampla distância a ser percorrida até a efetiva nomeação, cuja concretização dependia da intervenção do coronel.

São candidatoas a essas aulas, respectivamente, os Snrs. Frederico Guilherme Jaeger e Antonio Mariante de Campos já habilitados para esse fim em concurso.

Saudações cordiais do Vosso co-religionario e amigo 
Thomas Pereira (IHGRGS, 1906, Documento 10401).

Da mesma forma, o acesso a gratificações, vantagens e boas colocações (devido a fatores como distâncias, instalações ou quantidade de alunos, as classes poderiam ser mais ou menos disputadas pelos professores) dependia do poder de inserção do educador nessa rede de reciprocidades. 5 Os professores substitutos, por serem nomeados diretamente pelo interventor municipal, participavam ainda mais diretamente da rede de compromissos coronelistas, uma vez que tanto a sua nomeação quando a sua permanência no cargo dependiam de sua atuação, não apenas à frente da docência de sua classe, mas também no voto e na arregimentação de eleitores na localidade em que residia (AXT, 2011, p. 133-134).

Este contexto proporcionou, inclusive, o deslocamento de professores de outros estados da Federação para o Rio Grande do Sul. O investimento estadual no âmbito da educação e a demanda por docentes diplomados no magistério que levou o Estado a admitir professores formados, desde que com as devidas premissas do diploma comprovado, de outros estados para lecionar dentro do Rio Grande do Sul. ${ }^{6}$

5 "Funccionam regularmente 4 aulas estadoaes, 11 subvencionadas pelo governo do Estado e 20 municipaes. Com custeio destas, inclusive gratificação concedida a 8 professores subvencionados, o município dispendeu até 31 de outubro, a importância de Rs. 11:285\$666”. AHMG. Relatórios da Intendência do Município de Guaporé. Intendente Agilberto Attílio Maia, ano de 1913, p.5.

6 "Itapetininga, 10 de Novembro de 1904. Exmo. Sr. Presidente do Estado de S. Pedro do Rio Grande do Sul. Saúdo-o. Eu soube que V. Exa. acceita professores formados em outros estados e reconhece como validos os diplomas apresentados por elles, mediante provas irrecusáveis da sua veracidade.Em virtude dessa noticia, atrevo-me a pedir a V. Exa., informações sobre o caso.Consta mais que, V. Exa. de accordo com a lei orçamentaria desse tradicional e futuroso Estado, fixou aos professores, por V. Exa. reconhecidos, o ordenado de $300 \$ 00$ mensaes. Si for exacto o que aqui consta, peço a V. Exa. o especial obsequio de me responder.Sou professor diplomado pela Escola Complementar desta cidade, como provarei, si necessário for, com o título que tenho em meu poder, e pretendo, si for verdade o que se propala, ir habitar nessas paragens, cujo clima é agradabilíssimo e saudável, afim de espalhar o pão do espirito nos nossos concidadãozinhos riograndeses. Desejo também saber quaes os direitos e deveres conferidos aos professores. Aguardando a resposta de V. Exa, subscrevo-me com toda consideração e respeito.De V. Exa. Compatriota e atento Correligionário Antonio da Silveira Mello”. Instituto Histórico e Geográfico do Rio Grande do Sul. Arquivo Borges de Medeiros. MELLO, Antonio da Silveira. Carta. Guaratinguetá, SP, 
A nomeação desdobrava-se em vínculos de lealdade e compromissos por parte do professor e seus familiares, acionados durante os pleitos, tanto através do exercício do seu voto e de seus dependentes, quanto como cabos eleitorais do coronel nas respectivas linhas ou distritos em que se encontravam instalados. Dessa forma, o magistério, com suas centenas de postos, era um misto de função pública e negócio privado, funcionando como instrumento de costura das relações entre poder central, coronéis e eleitores (AXT, 2011, p. 134).

A instituição para os postos do magistério, por professores recomendados pelo coronel local, não apenas demonstrava sua importância na estrutura de poder estadual, mas também aumentava seu prestígio frente à sociedade local, permitindo reforçar a rede de compromissos do coronel e seus laços clientelísticos de submissão e fidelidade. A inclusão deste fator nos permite compreender as constantes solicitações para abertura de aulas públicas por parte dos coronéis da região de colonização italiana a Borges de Medeiros, conforme carta de Thomas José Pereira Júnior em 1904:

Ilustre Cidadão Dr. Antonio Augusto Borges de Medeiros Hoje respondi a circular do Dr. Manoel Pacheco Prates, sobre localisação de aulas neste município. Nessa resposta inclui o pedido que verbalmente vos fiz, sobre a creação de mais duas aulas na linhas Tangerinas e Santa Eugenia.

Assim pois espero que não será elle esquecido.

Sudações cordiais do vosso co-religionario e amigo

Thomas Pereira (IHGRGS, 1904, Documento 10397).

Cooptação delineava-se como a ferramenta de construção do "pessoal do coronel”. Apresentava como limite a envergadura e o alcance de seu prestígio e influência erigido a partir de suas relações com as esferas de decisão, pública ou privada. $\mathrm{O}$ estabelecimento rede de compromissos local alcançava a proporção de sua capacidade não só de liderança, mas também de distribuição de favores, sempre obedecendo ao critério da in-

10/11/1904. 2 folhas. Documento 11963. Descritores: Política Nacional, Funcionalismo. 
serção do postulante na rede de compromissos e os serviços prestados ao coronel e ao partido, sobretudo às eleições.

Desse modo, as indicações para as nomeações dos quadros do magistério delineavam-se como mais uma engrenagem no aparelho de cooptação, elaborado residente do Estado em conjunto com os poderes locais, com o instituído de consolidar a posição, prestígio e rede de compromissos do coronel, suas esferas de atuação. Desse modo, as constantes solicitações para a abertura de aulas públicas continham, com raras exceções, a indicação do professor a ser nomeado para a referida aula, conforme percebemos nas palavras do Cel. Thomas José Pereira Júnior em 1906:

Exmo. Snr. Dr. Antonio Augusto Borges de Medeiros

Tomo a liberdade de lembrar-vos que prometteu-me converter em mixta a aula do sexo femino desta Villa, e nomear para Ella a professora Da. Maria do Carmo Pereira. A mesmo tempo, ouso pedir-vos que com a possivel brevidade façais a conversão da dita aula e a nomeação da professora referida.Saudo-vos cordialmente, subscrevendo-me com elevada consideração

Vosso co-religionario e att. Amigo

Thomas Pereira (IHGRGS, 1906, Documento 10404).

Cabe ressaltar que encontramos indícios importantes de que a prática de cooptação através da nomeação do professorado não se delineava como uma prática exclusiva do ensino de níveis iniciais. As constantes solicitações de nomeação para professor da Faculdade de Direito demonstrando que essa prática de cooptação percorria todos os âmbitos do ensino no Rio Grande do Sul. Conforme carta de Pacheco Patres, remetida de São Paulo em 25 de maço de 1915 a Borges de Medeiros, as nomeações para as cadeiras do ensino superior também passavam pela inserção dos postulantes na rede de compromissos estabelecida no Rio Grande do Sul.

Caro Borges.

Saudades. Aqui estou e sempre prompto para receber tuas ordens. O nosso amigo Dr. Honorio de Castilhos, por escripto, te não escreve e pede-me que o faça. Elle deseja ser nomeado professor substituto da Faculdade de Direito e agora existem duas vagas. Pede tua intervenção a seu favor. 
Disse-me ele que tem certeza de que te interessas por ele e que viu uma tua carta ao Herminio do Espirito Santo. O Honorio é integro e estudioso, e estou certo de que te não deixará mal caso seja nomeado. E também teu admirador (IHGRGS, 1915, Documento 12002).

Entretanto se, por um lado, a educação era tida como uma poderosa forma de cooptação das populações coloniais, em contrapartida, poderia significar também um problema para os coronéis frente às intendências. Esta situação pode ser bem compreendida na carta remetida de Antônio Prado pelo intendente Oswaldo Hampe, que após ser questionado por Borges de Medeiros justifica a diferença de 99 votos ocorrida na eleição de 1922 para 1926, expõe a relação entre a educação e a política no período. Hampe pondera que "há effectivamente razão de chamardes a nossa attenção sobre este facto", elencando os fatores que contribuíram para tal resultado, argumenta que o analfabetismo teve relevante peso.

Chegou ao nosso poder vosso telegrama de congratulações pelo resultado da última eleição. Nelle percebo que ficasteis tocado com a differença de 99 votos de 1922 para 1926. Há effectivamente razão de chamardes a nossa attenção sobre este facto. Contudo levarei a vossa ponderação os seguintes factos: [...]

g) $\mathrm{O}$ analphabetismo deste município contribue tambem, numa grande medida, para a deficiência de eleitores. [...] (IHGRGS, 1926, Documento 00162).

Delineamos também uma última, porém interessante, prática de cooptação empregada pelo Cel. Agilberto Attílio Maia, assim como pelos seus pares na região colonial. Em menor escala, mas também significativa, devido à falta de recursos o suficiente para a construção das instalações onde funcionariam as escolas públicas, o governo estadual e o governo municipal acabavam por alugar estabelecimentos, em geral às próprias casas dos professores que residiam no interior dos distritos do município, para a instalação das aulas.

Esse método não apenas funcionava em cooptação do eleitorado através do atendimento da demanda local pela criação das aulas e da nomeação do professor, mas também da vinculação do professor e de sua família com o aluguel do estabelecimento que, em caso de descompasso 
com a vontade do coronel, poderia ser facilmente alterado para outro edifício local. Com parcos recursos para obras, o Estado remunerava muitos professores para darem aula em suas próprias casas, os quais, com frequência, quando eram construídos prédios para as escolas, resistiam em transferir suas classes para aquelas dependências (AXT, 2011, p. 134).

Ressaltamos que a impressionante atenção despendida com a educação pelos coronéis da região de colonização italiana, assim como por Borges de Medeiros, devia-se a questões de variadas ordens. Além da inequívoca melhoria geral nos padrões de vida da população municipal, e as abissais vantagens políticas oferecidas pelas práticas de cooptação de eleitores e fortalecimento da rede de compromissos, o investimento em educação delineava-se como uma ferramenta peculiar de criação de exércitos de novos eleitores, uma vez que a alfabetização constituía um requisito para o sufrágio, elemento capital para a política de legitimidade, estabilidade e continuísmo de Borges de Medeiro. Além disto, projetando também a ascensão política do Rio Grande do Sul na política nacional, fazendo frente à Bahia, Rio de Janeiro e mesmo Minas Gerais e São Paulo como potência eleitoral (AXT, 2011, p. 133-134).

A educação era ponto nevrálgico para a sustentação política de Borges de Medeiros e do PRR, assim como da elevação do status do Rio Grande do Sul na política em nível nacional. Conforme a análise de Love, esse aumento exponencial no número de eleitores pode ser visualizado quando abordamos os números de 1898, quando Castilhos norteou o partido a abstenção nas eleições, o Rio Grande do Sul forneceu apenas aproximadamente três mil votos para presidente, enquanto que em 1906 esse número ascendia ao dígito de aproximadamente 42 mil votos, legando o Rio Grande do Sul à terceira posição entre os estados por número de eleitores, ultrapassando o Estado baiano e assumindo o posto de importante ator no palco da política nacional (LOVE, 1975, p. 146).

Este contexto proporcionava inclusive a contratação de professores voltados especialmente para o ensino da língua nacional e alfabetização dos imigrantes, com o desígnio de promover incremento do alistamento eleitoral. O Cel. Thomas José Pereira Júnior, em 1906, remete carta a 
Borges de Medeiros com o objetivo de comunicar quais eram os professores particulares comprometidos a ensinar a língua vernácula, citando então os nomes de "Frederico Guilherme Jaeger, em Sapé, Eduardo Hass, em Theuminha, Mathias Gautsch, na Brasil, Alberto Suckem na Jaeger e Antonio Mariante de Campos, na Tangerinas" (IHGRGS, 1906, Documento 10399).

Quanto ao funcionamento burocrático do magistério, a partir do mês de janeiro de cada ano letivo, era estabelecido pelo diretor-geral e pelos diretores regionais da instrução pública, oriundos da Secretaria do Interior e Justiça, os quadros do magistério, com base nos quais distribuíam os professores e fixavam-se as remunerações, segundo as vantagens e suplementares de direito devidos a cada professor e que, de forma invariável, eram concedidos particularmente por meio de decretos oficiais segundo o comprometimento do docente com a causa estadual. Em determinadas cidades, a prerrogativa sobre composição dos quadros era outorgada ao chefe político local. Essa prática, bastante difundida do início do período Borges, devido à necessidade de cooptação de correligionários e eleitores nos municípios, diminuiu sensivelmente durante a década de 1920, quando os chefes políticos, ao invés de montar o conjunto do quadro do magistério para a região, se limitavam a indicações pontuais (AXT, 2011, p. 134).

No município de Guaporé, essa prerrogativa permaneceu nas mãos do Cel. Agilberto Attílio Maia, como uma de suas principais ferramentas de barganha, sendo que a permanência dessa prerrogativa junto a gama de poderes do Cel. Attílio Maia explica a ausência de cartas destinadas a Borges de Medeiros solicitando a nomeação do magistério de Guaporé.

\footnotetext{
Actos $[\ldots]$

Nomêa a Srta. ErnestaMartinazzo professora publica municipal. Coronel Agilberto Attílio Maia, intendente de Guaporé, etc.

Usando das attribuições que lhe são conferidas pelo n. ${ }^{\circ} 8$, art 11, da Lei Orgânica, resolve nomear, nesta datam como de facto nomeada fica, a Srta. Ernesta Martinazzo, professora publica, para reger a aula $n^{0} 35$, localisada na estrada Gal. Osorio, lote n. ${ }^{\circ} 3 \mathrm{n}$ no $3^{\mathrm{o}}$ districto, com os vencimentos marcados mensaes, de $60 \$ 000$.
} 
Registre-se, publique-se e communique-se (AHMG. Relatórios da Intendência do Município de Guaporé, 1916, p. 81).

As práticas coronelistas apresentavam um conjunto de princípios que regiam e orientavam a conduta e relações entre coronéis e seus dependentes. A delimitação entre as esferas do público e do privado, do particular e do coletivo nessa sociedade era tênue e não plenamente definida, sendo espontaneamente cruzada em nome do estabelecimento de compromissos. Sem nenhum risco de quebra da moral tanto do solicitante quanto do concessor. Significava o estabelecimento de sentimentos de autoridade, prestígio, consideração, obediência, lealdade etc.

Isso posto podemos compreender a prática de cooptação por meio de provimento de cargos públicos não como um desvio do processo político, mas como um elemento constitutivo do fazer político da época, uma vez que a outorga do benefício estabelecia vínculos de compromissos numa relação de reciprocidade entre os coronéis e os dependentes que tornavam a sua ação legítima, a partir do prisma presente.

Em suma, compreendemos que a educação na região de colonização italiana esteve diretamente ligada às práticas de cooptação empregadas pelos coronéis ali estabelecidos. Ressaltamos que as aulas públicas estabelecidas dentro deste contexto, embora muitas vezes efêmeras em duração ou mesmo em número de alunos, alcançaram um número relativamente considerável. $\mathrm{O}$ alcance, tanto da rede de compromissos estabelecida entre coronéis e professores, quanto a cooptação dos imigrantes e seus descendentes através do estabelecimento de aulas públicas e a alfabetização com seus consequentes resultados nos processos eleitorais, pode ser mensurado e compreendido quando analisamos a evolução dos números totais de aulas subvencionadas pelo Cel. Agilberto Attílio Maia entre 1913 e 1923, no município de Guaporé.

Entre o período que compreende os dez anos entre 1913 e 1923, o número de aulas públicas subvencionadas pelo governo municipal e estadual salta de 34 para 86, ilustrando a estima conferida à educação, tanto na formação e doutrinação de eleitores, quanto no estabelecimento da rede de compromissos ligada ao magistério, tendo crescido gradativa- 
mente: 34 em 1913, 64 em 1916, 81 em 1920 e 86 em 1923. Havendo também gradativo crescimento no número de alunos atendidos.

Em 1912, ano da eleição do Cel. Agilberto Attílio Maia para o cargo de intendente, Guaporé contava com 26 aulas públicas e um total de 1.732 alunos matriculados. Em 1926, após dez anos de sua administração, as cifras alcançavam 86 aulas e 3.416 matrículas. Esses dados fornecem um vislumbre do processo de ampliação da rede de compromissos coronelista estabelecida pelo Cel. Attílio Maia, cooptando não apenas os eleitores ligados ao quadro de professores nomeados para o magistério, mas também de cooptação dos eleitores das áreas rurais através da consideração de suas demandas por educação.

\section{Conclusão}

A relação entre o coronel da região de colonização italiana e o presidente do Estado pode ser entendida da seguinte forma: embora sua autonomia fosse diretamente enfraquecida, pela centralização monolítica e hierárquica do PRR, o coronel utilizava-se do aparelho estruturado por ele para suas práticas de cooptação e coerção, cristalizando sua posição, frente à esfera estadual e local. Assim, o coronel aceitava e integrava-se como uma engrenagem na máquina política borgista, ao invés de lutar contra sua centralização.

Entretanto, descartamos uma relação vertical de poder, ou uma simples burocratização do coronel, ao passo que identificamos uma relação de compromissos e interdependências que permeava eleitores, coronel e presidente do Estado, sendo que todas as esferas contraíam obrigações e compromissos que deveriam ser atendidos em suas ocasiões competentes. Estado e coronéis dependiam dessa interação para a manutenção de suas posições de poder. Essa rede de obrigações e compromissos interligava desde o chefe político estadual e o coronel local, passando pelo professor nomeado e sua família, até alcançar os imigrantes e descendentes que ansiavam pelo estabelecimento das aulas. 


\section{Referências}

A FEDERAÇÃO, Porto Alegre, 17 de fevereiro de 1913. Ano 1913 - Arquivo o0041. Disponível em: <http://memoria.bn.br/hdb/periodico.aspx>. Acesso em: $1^{\circ}$ abr. 2015.

AXT, G. Gênese do estado moderno no Rio Grande do Sul (1889-1929). Porto

Alegre: Paiol, 2011.

COSTA, R. Imigração Italiana no Rio Grande do Sul: vida, costumes e tradições. $2^{\mathrm{a}}$. impressão revista. Porto Alegre: EST, 1986.

LOVE, J. O regionalismo gaúcho e as origens da revolução de 1930. São Paulo: Perspectiva, 1975, p. 146.

LUCHESE, T. Â.; KREUTZ, L. Educação e etnia: as efêmeras escolas étnico-comunitárias italianas pelo olhar dos cônsules e agentes consulares. In: História da Educação, ASPHE/FaE/UFPel, Pelotas, v. 14, n. 30, Jan./Abr. 2010, p. 227-258.

LUCHESE. T. Â. Em busca da escola pública: tensionamentos, iniciativas e processo de escolarização na região colonial italiana, Rio Grande do Sul, Brasil. In: Cadernos de História da Educação, v. 11, n. 2 - jul./dez. 2012, p. 667-679.

MANFRÓI, O. A colonização italiana no Rio Grande do Sul: implicações econômicas, políticas e culturais. Porto Alegre: Grafosul, 1975.

\section{Documentos (cartas)}

IHGRGS. Arquivo Borges de Medeiros. PEREIRA JR., Thomaz José. Carta. Venâncio Aires, RS, 10/3/1903. 2 folhas. Documento 10390. Descritores: Municípios, Funcionalismo.

IHGRGS. Arquivo Borges de Medeiros. PEREIRA JR., Thomaz José. Carta. Venâncio Aires, RS, 12/12/1904. 1 folha. Documento 10397. Descritores: Municípios, Educação.

IHGRGS. Arquivo Borges de Medeiros. MELLO, Antonio da Silveira. Carta. Guaratinguetá, SP, 10/11/1904. 2 folhas. Documento 11963. Descritores: Política Nacional, Funcionalismo. 
IHGRGS. Arquivo Borges de Medeiros ABREU, Firmino Luiz Gomes de. Carta. Antonio Prado, RS, 23/5/1905. 2 folhas. Documento 00146. Descritores: Política Regional, Funcionalismo.

IHGRGS. Arquivo Borges de Medeiros. PEREIRA JR., Thomaz José. Carta. Venâncio Aires, RS, 23/2/1906. 2 folhas. Documento 10398. Descritores: Municípios, Funcionalismo.

IHGRGS. Arquivo Borges de Medeiros. PEREIRA JR., Thomaz José. Carta. Venâncio Aires, RS, 16/7/1906. 2 folhas. Documento 10401. Descritores: Municípios, Funcionalismo.

IHGRGS. Arquivo Borges de Medeiros. PEREIRA JR., Thomaz José. Carta. Venâncio Aires, RS, 2/4/1906. 1 folha. Documento 10404. Descritores: Funcionalismo, municípios, Educação.

IHGRGS. Arquivo Borges de Medeiros. MORAES, Geraldina de. Carta. Antonio Prado, RS, 19/5/1907. 2 folhas. Documento 00152. Descritores: Política Regional, Funcionalismo.

IHGRGS. Arquivo Borges de Medeiros. PRATES, M. Pacheco. Carta. São Paulo, SP, 25/3/1915. 2 folhas. Documento 12002. Descritores: Política Nacional, Funcionalismo.

IHGRGS. Arquivo Borges de Medeiros. MAIA, Agilberto Attílio. Carta. Guaporé, RS, 20/4/1915. 3 folhas. Documento 02460. Documento 02468. Descritores: Obras Públicas, Municípios.

IHGRGS. Arquivo Borges de Medeiros. HAMPE, Hampe. Carta. Antonio Prado, RS, 14/3/1926. 5 folhas. Documento 00162. Acompanha o documento de $\mathrm{n}^{0}$ 00162. Descritores: Partidos Políticos, Municípios, Executivo Municipal, Partido Republicano Rio-Grandense.

\section{Documentos (relatórios intendência)}

AHMG. Relatórios da Intendência do Município de Guaporé. Intendente Lucano Conedera, ano de 1910.

AHMG. Relatórios da Intendência do Município de Guaporé. Intendente Agilberto Attílio Maia, ano de 1913, 1915, 1916, 1917, 1920, 1923. 